\title{
Sensory Input Directs Spatial and Temporal Plasticity in Primary Auditory Cortex
}

\author{
MICHAEL P. KILGARD, ${ }^{1,2}$ PRITESH K. PANDYA, ${ }^{1}$ JESSICA VAZQUEZ, ${ }^{1}$ ANIL GEHI, ${ }^{2}$ \\ CHRISTOPH E. SCHREINER, ${ }^{2}$ AND MICHAEL M. MERZENICH ${ }^{2,3}$ \\ ${ }^{1}$ Neuroscience Program, School of Human Development, University of Texas at Dallas, Richardson, Texas 75083-0688; \\ ${ }^{2}$ Coleman Laboratory, Departments of Otolaryngology and Physiology, Keck Center for Integrative Neuroscience, \\ University of California at San Francisco, San Francisco 94143-0444; and ${ }^{3}$ Scientific Learning Corporation, \\ Berkeley, California 94104-1075
}

Received 21 September 2000; accepted in final form 9 January 2001

\begin{abstract}
Kilgard, Michael P., Pritesh K. Pandya, Jessica Vazquez, Anil Gehi, Christoph E. Schreiner, and Michael M. Merzenich. Sensory input directs spatial and temporal plasticity in primary auditory cortex. $J$ Neurophysiol 86: 326-338, 2001. The cortical representation of the sensory environment is continuously modified by experience. Changes in spatial (receptive field) and temporal response properties of cortical neurons underlie many forms of natural learning. The scale and direction of these changes appear to be determined by specific features of the behavioral tasks that evoke cortical plasticity. The neural mechanisms responsible for this differential plasticity remain unclear partly because important sensory and cognitive parameters differ among these tasks. In this report, we demonstrate that differential sensory experience directs differential plasticity using a single paradigm that eliminates the task-specific variables that have confounded direct comparison of previous studies. Electrical activation of the basal forebrain (BF) was used to gate cortical plasticity mechanisms. The auditory stimulus paired with BF stimulation was systematically varied to determine how several basic features of the sensory input direct plasticity in primary auditory cortex (A1) of adult rats. The distributed cortical response was reconstructed from a dense sampling of A1 neurons after 4 wk of BF-sound pairing. We have previously used this method to show that when a tone is paired with $\mathrm{BF}$ activation, the region of the cortical map responding to that tone frequency is specifically expanded. In this report, we demonstrate that receptive-field size is determined by features of the stimulus paired with BF activation. Specifically, receptive fields were narrowed or broadened as a systematic function of both carrier-frequency variability and the temporal modulation rate of paired acoustic stimuli. For example, the mean bandwidth of A1 neurons was increased $(+60 \%)$ after pairing BF stimulation with a rapid train of tones and decreased $(-25 \%)$ after pairing unmodulated tones of different frequencies. These effects are consistent with previous reports of receptive-field plasticity evoked by natural learning. The maximum cortical following rate and minimum response latency were also modified as a function of stimulus modulation rate and carrier-frequency variability. The cortical response to a rapid train of tones was nearly doubled if $\mathrm{BF}$ stimulation was paired with rapid trains of random carrier frequency, while no following rate plasticity was observed if a single carrier frequency was used. Finally, we observed significant increases in response strength and total area of functionally defined A1 following $\mathrm{BF}$ activation paired with certain classes of stimuli and not others. These results indicate that the degree and direction of cortical plasticity of temporal and receptive-field selectivity are specified by the
\end{abstract}

Address for reprint requests: M. P. Kilgard, Neuroscience Program, School of Human Development, GR 41, University of Texas at Dallas, Richardson, TX 75083-0688 (E-mail: kilgard@utdallas.edu). structure and schedule of inputs that co-occur with basal forebrain activation and suggest that the rules of cortical plasticity do not operate on each elemental stimulus feature independently of others.

\section{N T R O D U C T I O N}

Experiments conducted over the last 20 years have documented that cortical representations are continually shaped by experience (Buonomano and Merzenich 1998; Edeline 1999; Gilbert 1998; Katz and Shatz 1996; Merzenich et al. 1996; Singer 1995). Numerous studies have suggested that experience-dependent plasticity provides the neural basis for the substantial improvement in performance that typically develops with extended practice on simple discrimination tasks. In animal models of learning, both spatially and temporally based tasks lead to progressive improvements in behavioral performance; however, the form of neural plasticity that underlies these improvements can be quite distinct. For example, receptive fields in the somatosensory cortex of New World monkeys are substantially increased by training on temporal judgements, while fine tactile manipulations decrease receptive-field sizes (Jenkins et al. 1990; Recanzone et al. 1992c; Wang et al. 1995). A more complete description of the rules that transform sensory experience into useful changes in the distributed cortical representation is needed 1 ) to relate the cellular rules of synaptic plasticity to observed experience-dependent plasticity in large populations of neurons, and 2) to clarify how these rules contribute to both the flexibility and reliability of the integrated operation of cell assemblies operating across the cortex.

Although it is clear that the degree and direction of cortical plasticity depends on the behavioral paradigm used to produce it, it is not yet clear what specific aspects of these different experiences are responsible for the distinct forms of observed cortical reorganizations. Studies of experience-dependent plasticity often differ in a number of parameters likely to be important for determining the form of plasticity, including modality, behavioral response, task difficulty, task goal, motivation, duration of training, background stimuli, and species (Bakin et al. 1992, 1996; Buonomano and Merzenich 1998;

\footnotetext{
The costs of publication of this article were defrayed in part by the payment of page charges. The article must therefore be hereby marked "advertisement" in accordance with 18 U.S.C. Section 1734 solely to indicate this fact.
} 
Byl et al. 1996; Diamond and Weinberger 1989; Dimyan and Weinberger 1999; Edeline et al. 1993; Glazewski 1998; Recanzone et al. 1992b-d; Sakai et al. 1999; Spengler et al. 1997; Wang et al. 1995; Xerri et al. 1996; Zohary et al. 1994). Although several studies have explored how parameters such as attention and task difficulty affect plasticity (Ahissar and Hochstein 1997; Ahissar et al. 1992; Edeline and Weinberger 1993; Recanzone et al. 1992c, 1993), relatively little is known about how specific features of behaviorally important stimuli direct cortical reorganization. In this study, we employ a powerful technique that mimics learning-induced plasticity to document how simple alterations of the sensory input produce substantially different forms of cortical plasticity (Juliano 1998; Kilgard and Merzenich 1998a,b).

Activity of cholinergic neurons in the basal forebrain (BF) provides a gate on plasticity mechanisms that allows the cortex to operate specifically on behaviorally arousing stimuli (Hasselmo 1995; Singer 1986; Weinberger 1993; Woody 1982). Nucleus Basalis (NB) neurons provide the major source of cholinergic input to the neocortical mantle (Mesulam et al. 1983) (Fig. 1A) and contribute a significant GABAergic input as well (Gritti et al. 1997). These neurons project ipsilaterally to all of the neocortex, as well as to the amygdala and the reticular nucleus of the thalamus (Levey et al. 1987; Mesulam et al. 1983), and receive inputs from the amygdala, ventral tegmentum, frontal cortex, hypothalamus, and from a number of brain stem nuclei (Haring and Wang 1986). NB neurons respond to both aversive and rewarding stimuli of different modalities and can be conditioned to respond to innocuous stimuli that become associated with reward (Pirch 1993; Richardson and DeLong 1991; Whalen et al. 1994).

Lesion studies support the hypothesis that NB activity serves as a reinforcement signal to guide cortical plasticity. Even the robust cortical reorganization that follows digit amputation, nerve section, or monocular deprivation can be blocked by NB lesions (Bear and Singer 1986; Juliano et al. 1991; Webster et al. 1991a). Highly selective lesions of only the cholinergic neurons in the NB prevent the plasticity that results from whisker trimming or follicle removal (Baskerville et al. 1997; Sachdev et al. 1998; Zhu and Waite 1998), providing strong evidence that NB is necessary for cortical map reorganizations.

The role of NB activity in gating cortical plasticity was further supported by experiments in auditory and somatosensory cortex of rats, guinea pigs, cats, and raccoons, demonstrating that pairing electrical activation of NB with sensory stimuli is sufficient to shift cortical receptive fields (Bakin and Weinberger 1996; Bjordahl et al. 1998; Edeline et al. 1994a,b; Hars et al. 1993; Howard and Simons 1994; Kilgard and Merzenich 1998a; Tremblay et al. 1990; Webster et al. 1991b), and temporal response properties (Kilgard and Merzenich 1998b; Shulz et al. 2000). Many of these experiments showed that NB-induced plasticity is blocked by atropine, a cholinergic antagonist. Introducing a 1-s separation between the sensory input and NB activation also blocked NB-induced plasticity (Metherate and Ashe 1991, 1993). Collectively, these results indicate that NB activity serves as a powerful modulator of cortical plasticity mechanisms.

Although cortical plasticity results from a medley of manipulations of sensory experience, it has generally been difficult to directly compare the results from such studies. In this study, the modality, species, behavioral state, and number of repeti-
A

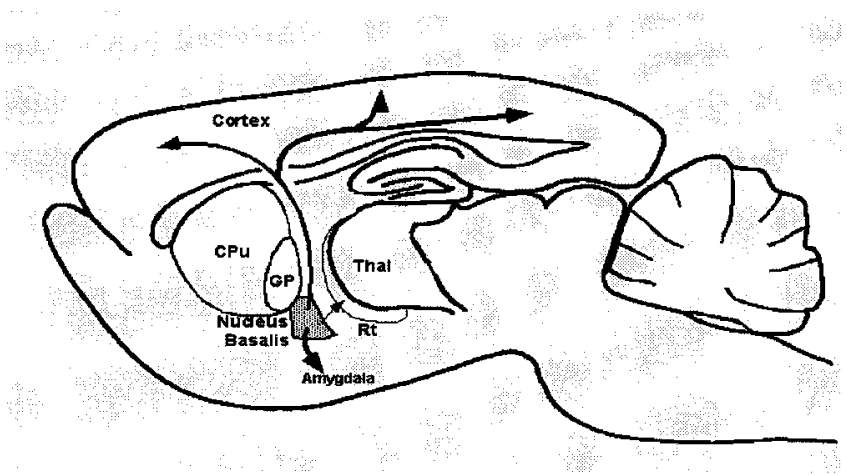

B

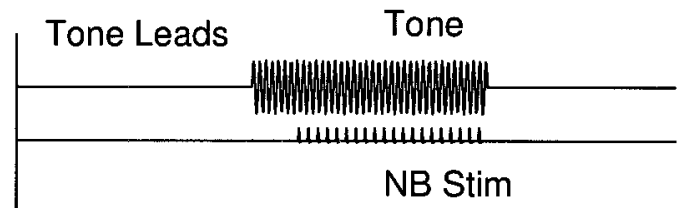

Tone Lags

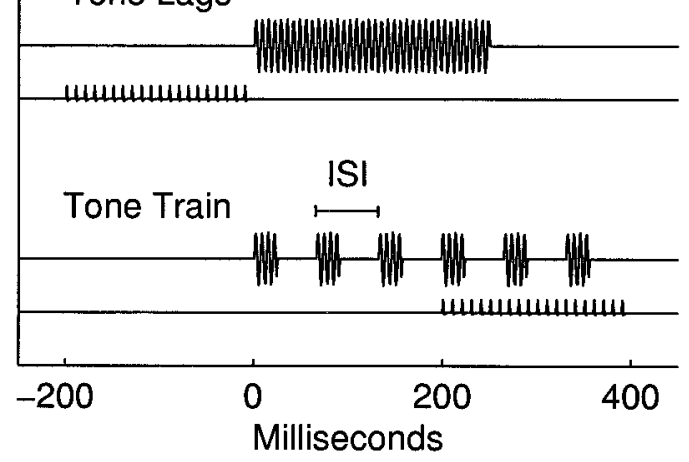

C

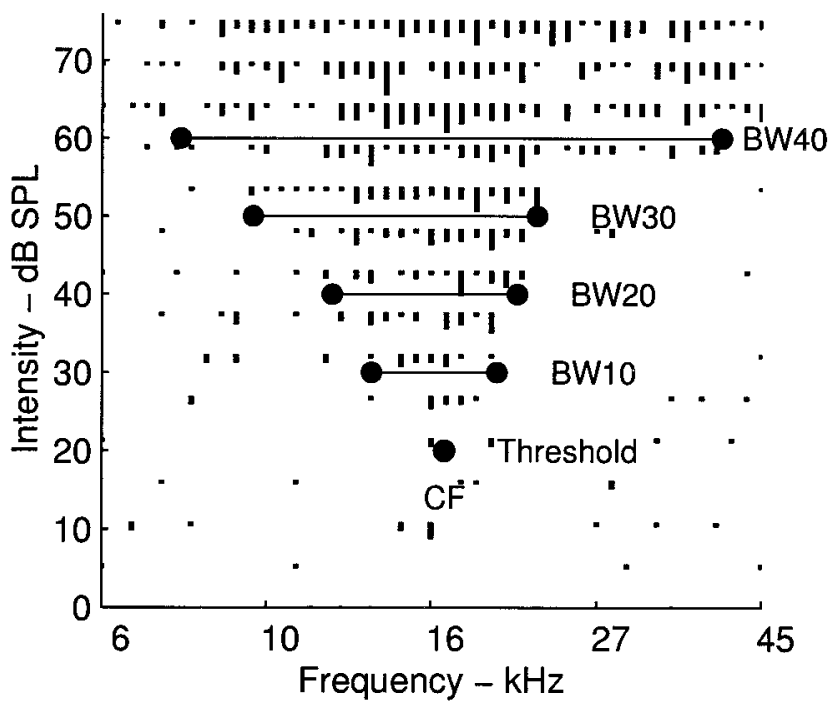

FIG. 1. A: projections from Nucleus Basalis (NB) to the neocortex, reticular thalamus, and amygdala. $B$ : relative timing of tonal stimuli and basal forebrain $(\mathrm{BF})$ activation. $C$ : diagram of representative primary auditory cortex (A1) tuning curve with relevant features labeled. Length of line segments indicates the number of spikes evoked by each tone. Characteristic frequency $(\mathrm{CF})$ is the frequency that elicits a consistent neural response at the lowest intensity, threshold. Bandwidth (BW) is the range of frequencies the neurons are responsive to at the specified intensity above threshold, expressed in octaves. 
tions are the same across experimental groups that vary only in acoustic experience. The sound stimulus paired with BF activation was varied along a number of stimulus continua in different animals to explore how the structure and schedule of auditory input guides plasticity of spectral and temporal response properties. We also explored the effect of introducing a delay between tone onset and BF activation. Our results are consistent with previous studies of experience-dependent cortical plasticity in primates and document in greater detail how spectral and temporal features of the sensory input specify the direction and magnitude of receptive field and temporal response plasticity in primary auditory cortex (A1).

\section{METHOD S}

\section{Implantation and stimulation}

BF-stimulating electrodes were implanted in 38 pentobarbital anesthetized $(50 \mathrm{mg} / \mathrm{kg})$ rats $(\sim 300 \mathrm{~g})$. Platinum bipolar-stimulating electrodes (SNE-200, Rhodes Medical Instruments, Woodland Hills, CA) were lowered $7.0 \mathrm{~mm}$ below the cortical surface $3.3 \mathrm{~mm}$ lateral and $2.3 \mathrm{~mm}$ posterior to bregma and cemented into place using sterile techniques approved under University of California at San Francisco and University of Texas at Dallas animal care protocols. Rats received prophylactic treatment with ceftizox antibiotic $(20 \mathrm{mg} / \mathrm{kg})$, dexamethazone $(4 \mathrm{mg} / \mathrm{kg})$, and atropine $(1 \mathrm{mg} / \mathrm{kg})$. Three bone screws were used to anchor the electrode assembly. Leads were attached to screws over the cerebellum and cortex so that the global electroencephalograph (EEG) could be monitored during BF activation in unanesthetized animals.

After 2 wk of recovery, tonal stimuli were paired with BF electrical stimulation in a sound-shielded test chamber ( 5 days/wk) for 1 mo (Table 1 ). Animals were placed in a $25 \times 25-\mathrm{cm}$ wire cage in the middle of $60 \times 70-\mathrm{cm}$ box lined with 3 -in acoustic foam. The cage was positioned $20 \mathrm{~cm}$ below the audio speaker. A small 4-pin connector attached to a swivel was used to record the EEG and to deliver short current pulses to the stimulating electrode. Each animal received 300-500 pairings of tones and BF stimulation per day. Interstimulus intervals varied randomly from 10 to $30 \mathrm{~s}$. Ten rats received $\mathrm{BF}$ stimulation paired with a $70 \mathrm{~dB}$ SPL tone with a fixed frequency (4, 9 , or $19 \mathrm{kHz}$ ). In five rats, two different randomly interleaved tone frequencies were paired with BF stimulation (4 and 14 or 9 and 19
$\mathrm{kHz}$ ). In five rats, nine different randomly interleaved tone frequencies were paired with BF stimulation $(1.3,2,3,4,5,7,9,11.2$, and 14 $\mathrm{kHz}$ ). In this group, tones were presented at 30-40 dB above rat hearing threshold (Kelly and Masterton 1977) to activate similarly sized neural populations. In four rats, a train of six short $9-\mathrm{kHz}$ tones presented at 15 pulses per second (pps) were paired with BF stimulation. In 10 rats, trains of short tones applied at a constant tone frequency which varied randomly from trial to trial $(1.3,2,3,5,9,14$, or $19 \mathrm{kHz}$ at $20-30 \mathrm{~dB}$ above threshold). The repetition rate of the tones was fixed for each animal $(5,7.5$, and $15 \mathrm{pps}, n=4,2$, and 4 rats, respectively). All tones had 3-ms onset and offset ramps. The tones paired with BF stimulation were $250 \mathrm{~ms}$ in duration except for the tone trains that were composed of $25-\mathrm{ms}$ tones.

To establish the specificity of BF pairing, several animals were also stimulated with tones that were not paired with BF stimulation. Half of the animals in the single-frequency group were also presented, on the same schedule, with two other tone frequencies not paired with BF stimulation (see Table 1). There were no unpaired stimuli delivered to the $9 \mathrm{kHz} / 15$-pps rats. The multiple-frequency train groups heard one of each of the multiple-frequencies tone pips presented in isolation without BF stimulation as often as they heard each train that was paired with BF stimulation.

When a single unmodulated tone was used as the auditory stimulus (one frequency group), electrical stimulation began $50 \mathrm{~ms}$ after tone onset in half the experiments and $200 \mathrm{~ms}$ before tone onset in the other half (Fig. 1B). Although some forms of learning are very sensitive to the order of sensory and modulatory inputs, these two relative timings did not generate noticeably different plasticity effects, and the two groups are analyzed together in this study. In the multiple-carrier frequency groups, electrical stimulation began $50 \mathrm{~ms}$ after tone onset. When tone trains were used, stimulation occurred simultaneously with the onset of the fourth tone in trains. In four animals, $19-\mathrm{kHz}$ tones were presented $10 \mathrm{~s}$ after each BF stimulation. BF stimulation consisted of 20 capacitatively coupled biphasic pulses (0.1-ms pulse width, 100 pulses/s).

The efficacy of BF activation was continuously monitored in every animal by quantifying BF-induced EEG desynchronization during slow-wave sleep. The current level $(70-150 \mu \mathrm{A})$ for BF stimulation was chosen for each animal to be the minimum necessary to desynchronize the EEG for 1-2 s during slow-wave sleep. After observing many naturally occurring sleep-wake cycles in each animal using video monitoring, we determined a level of EEG power (from 1 to 5 $\mathrm{Hz}$ ) that distinguished the two states (i.e., always below while awake

TABLE 1. Summary of experiments

\begin{tabular}{|c|c|c|c|c|c|}
\hline Experiment Group & $\begin{array}{l}\text { Parameters } \\
\text { Varied }\end{array}$ & $\begin{array}{c}\text { Auditory Stimuli Paired With BF } \\
\text { Stimulation }\end{array}$ & Unpaired Stimuli & $\begin{array}{c}\text { No. of } \\
\text { Rats }\end{array}$ & $\begin{array}{l}\text { No. of A1 } \\
\text { Sites }\end{array}$ \\
\hline Control & $\varnothing$ & $\varnothing$ & $\varnothing$ & 14 & 663 \\
\hline \multirow[t]{3}{*}{ One frequency } & Tone frequency & $4 \mathrm{kHz}$ & [2 and $9 \mathrm{kHz}]$ & 4 & 242 \\
\hline & & $9 \mathrm{kHz}$ & [4 and $19 \mathrm{kHz}$ ] & 4 & 233 \\
\hline & & $19 \mathrm{kHz}$ & [4 and $9 \mathrm{kHz}]$ & 2 & 112 \\
\hline \multirow{3}{*}{$\begin{array}{l}\text { Multiple-carrier } \\
\text { frequencies }\end{array}$} & Number of paired & 4 and $14 \mathrm{kHz}$ & 9 and $19 \mathrm{kHz}$ & 2 & 90 \\
\hline & frequencies & 9 and $19 \mathrm{kHz}$ & 4 and $14 \mathrm{kHz}$ & 3 & 119 \\
\hline & & $1.3,2,3,4,5,7,9,11.2$, and $14 \mathrm{kHz}$ & $\varnothing$ & 5 & 237 \\
\hline 15 pps $9 \mathrm{kHz}$ & $\begin{array}{l}\text { Repetition rate } \\
\text { and number of } \\
\text { frequencies }\end{array}$ & $15 \mathrm{pps}$ train of tones, $9 \mathrm{kHz}$ & $\varnothing$ & 4 & 224 \\
\hline 15 pps multi & & $15 \mathrm{pps}$ train of tones, multiple frequencies & Single tones of multiple frequencies & 4 & 223 \\
\hline 7.5 pps multi & & $7.5 \mathrm{pps}$ train of tones, multiple frequencies & Single tones of multiple frequencies & 2 & 92 \\
\hline 5 pps multi & & $5 \mathrm{pps}$ train of tones, multiple frequencies & Single tones of multiple frequencies & 4 & 175 \\
\hline $\begin{array}{l}\text { Delayed BF } \\
\text { stimulation }\end{array}$ & Relative timing & $19 \mathrm{kHz}-10 \mathrm{~s}$ after BF stimulation & $\varnothing$ & 4 & 206 \\
\hline Totals & & & & 52 & 2616 \\
\hline
\end{tabular}

Basal forebrain (BF) stimulation was paired with 10 classes of auditory stimuli. Four features of the paired auditory stimuli (tone frequency, number of tone frequencies, repetition rate, and onset timing) were varied to determine their effect on cortical plasticity. Brackets denote stimuli that were played in half of the one frequency experiments to determine the effect of unpaired stimuli. 
and usually above while sleeping). We used custom software to compare low-frequency EEG power during a 2-s period immediately before and after every stimulation event and set the current level $(70-150 \mu \mathrm{A})$ for BF stimulation to be the minimum level that desynchronized the EEG below the EEG threshold. Typically, rats were sleeping during $10-20 \%$ of stimulation events, and BF activation resulted in desynchronization for $75-95 \%$ of these events. Only trials with low-frequency EEG power above the threshold before stimulation were analyzed to determine effectiveness of BF activation. EEG desynchronization usually lasted 1-4 s. Tonal and electrical stimuli did not evoke any observable behavioral responses (i.e., did not cause rats to stop grooming, or awaken, if sleeping).

\section{Electrophysiological recordings and analysis}

This study is based on neuronal spike data collected from 2,616 microelectrode penetrations into the right primary auditory cortex in 52 adult female Sprague-Dawley rats. Surgical anesthesia was induced with pentobarbital sodium $(50 \mathrm{mg} / \mathrm{kg})$. Throughout the surgical procedures and during the recording session, a state of areflexia was maintained with supplemental doses of dilute pentobarbital $(8 \mathrm{mg} / \mathrm{ml}$ ip). The trachea was cannulated to ensure adequate ventilation and to minimize breathing-related noises. The skull was supported in a head holder that left the ears unobstructed. The cisternae magnum was drained of CSF to minimize cerebral edema. After reflecting the temporalis muscle, auditory cortex was exposed and the dura was resected. The cortex was maintained under a thin layer of viscous silicon oil to prevent desiccation. The location of each penetration was reproduced on a $\times 40$ digitized image of the cortical surface microvasculature.

The primary auditory cortex was defined on the basis of its shortlatency $(8-20 \mathrm{~ms})$ responses and its continuous tonotopy (preferred tone frequency increased from posterior to anterior, see Fig. 2, $A$ and B) (Kilgard and Merzenich 1999). Responsive sites that exhibited clearly discontinuous best frequencies and long-latency responses, unusually high thresholds, or very broad tuning were considered to be non-A1 sites. Penetration sites were chosen to avoid damaging blood vessels while generating a detailed and evenly spaced map. Voronoi tessellation (Matlab 5.2, MathWorks) was used to visualize the topography of A1. Voronoi tessellation generates polygons from each set of nonuniformly spaced recording sites such that every point within each polygon was nearer to the sampled site for that polygon than to any other site. The boundaries of the map were functionally determined using nonresponsive and non-A1 sites.

Recordings were made in a shielded, double-walled sound chamber (IAC). Action potentials were recorded simultaneously from two Parylene-coated tungsten microelectrodes (FHC, 250- $\mu \mathrm{m}$ separation, $2 \mathrm{M} \Omega$ at $1 \mathrm{kHz}$ ) that were lowered orthogonally into the cortex to a depth of $\sim 550 \mu \mathrm{m}$ (layers IV/V). The neural signal was filtered $(0.3-8 \mathrm{kHz})$ and amplified $(10,000 \times)$. Action potential waveforms were recorded whenever a set threshold was exceeded, allowing off-line spike sorting using Autocut (Datawave) or Brainware (TuckerDavis Technology) software. Although most responses in this study represented the spike activity of several neurons, single units were separated when possible, confirming that single units exhibited tuning that was qualitatively similar to multi-unit response samples. To minimize experimenter-induced sampling bias the experimenter was blind to the frequency(ies) paired with BF stimulation.

In most experiments, acoustic stimuli were delivered to the left ear via a calibrated ear phone (STAX 54) positioned just inside the pinnae. In the experiments with nine carrier frequencies, stimuli were presented with a calibrated speaker positioned $10 \mathrm{~cm}$ from the left ear. Because this system resulted in somewhat lower low-frequency thresholds, all analyses of these animals was compared with recordings from six experimentally naïve rats using the same speaker and position. Frequencies and intensities were calibrated using a B\&K sound-level meter and a Ubiquitous spectrum analyzer. Auditory
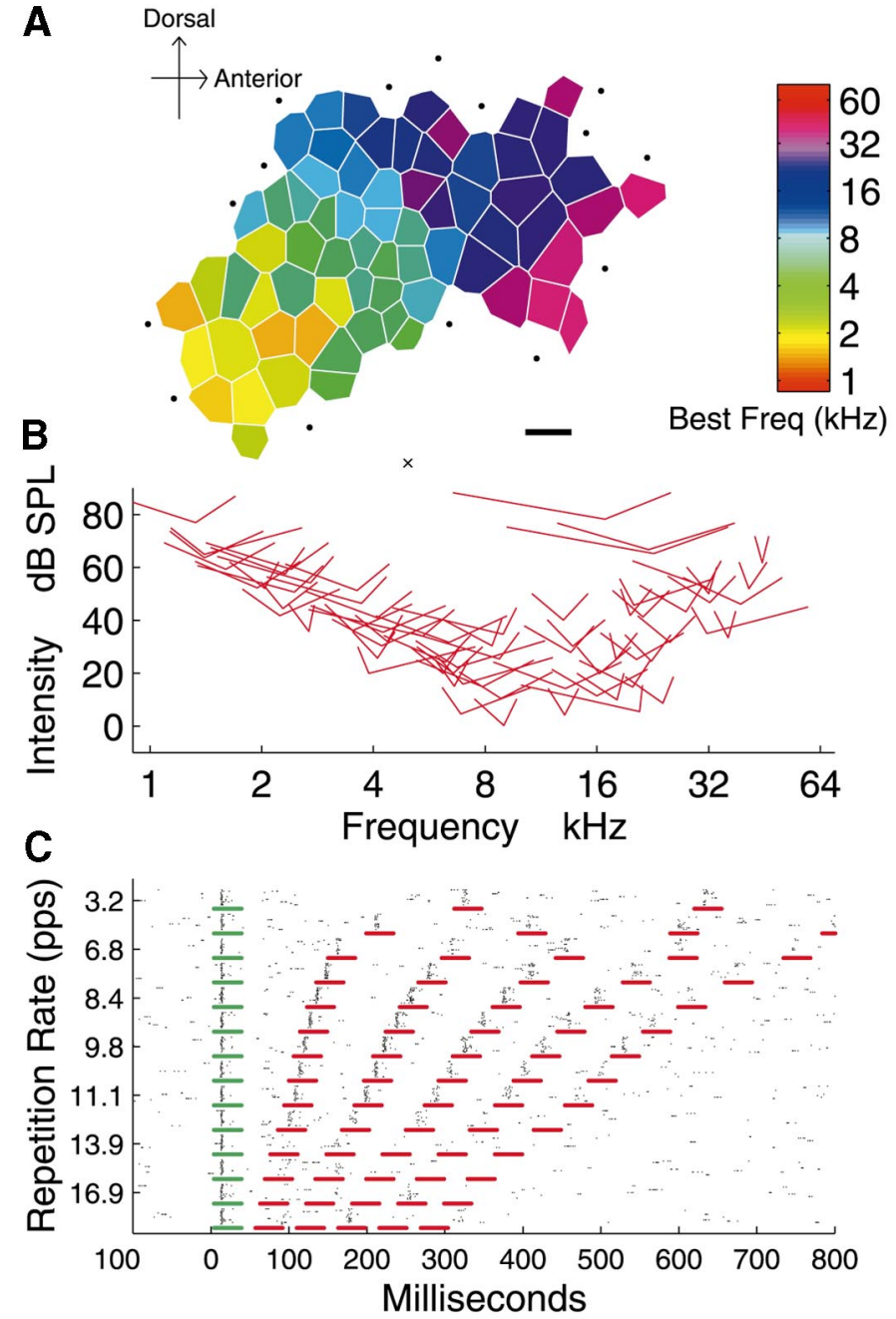

FIG. 2. A: representative CF map of primary auditory cortex from a naïve adult rat. Each polygon represents 1 electrode penetration. Color represents each site's best frequency. Nonresponsive and auditory responding non-A1 sites are marked with dots and x's, respectively. Scale bar $=250 \mu \mathrm{m}$. B: tuning curve tips for the rat in $A$. The tip of each $\mathrm{V}$ depicts minimum threshold for each site. Width of the V represents tuning curve width $10 \mathrm{~dB}$ above threshold. $C$ : representative example of the temporal selectivity of A1 neurons to tone trains. Most neurons in rat A1 do not respond to tones presented at rates exceeding 12 pulses/s. The dot raster indicates the responses to 12 repetitions of 16 rates. The short horizontal lines designate the spike collection windows used to generate the RRTF. Tone onsets occur $8 \mathrm{~ms}$ before each line.

frequency response tuning curves were determined by presenting 45 frequencies spanning 3-4.5 octaves centered on the approximate best frequency of the site, or 81 frequencies from 1 to $32 \mathrm{kHz}$. Each frequency was presented at 15 or 16 intensities ranging between 0 and $75 \mathrm{~dB}$ (either 675 or 1,296 total stimuli). Tuning curve tones were randomly interleaved and separated by $500 \mathrm{~ms}$. All tonal stimuli used during the acute phase of this study were 25-ms long, including 3-ms rise and fall times.

Rat A1 tuning curves were V-shaped and generally exhibited monotonic intensity response functions (Kilgard and Merzenich 1999; Sally and Kelly 1988). Tuning-curve parameters were defined by an experienced blind observer using custom software that displayed raw spike data without reference to the frequencies and intensities that generated the responses. For each tuning curve, best frequency, threshold, bandwidth $(10,20,30$, and $40 \mathrm{~dB}$ above threshold), and latency data were recorded (Fig. 1C). Characteristic frequency $(\mathrm{CF})$ is the frequency that evokes a consistent neural response at the lowest 
stimulus intensity. The minimum latency was defined as the time from stimulus onset to the earliest consistent response (defined by a blind observer) for any of 15 intensities of the three frequencies that were nearest the CF (45 stimuli). The end of response latency was defined as the time after tone onset when the PSTH (peristimulus time histogram) created by summing the responses to all of the tones within each site's tuning curve returned to baseline. Statistical analysis was done using Matlab 5.2. The specific test used was an unpaired twotailed $t$-test, unless otherwise indicated. Error bars reflect standard error of the mean.

To determine the repetition rate transfer function (RRTF) for each site, six tones ( $25 \mathrm{~ms}$ with 5-ms ramps, $70 \mathrm{~dB}$ SPL) were presented 12 times at each of 16 repetition rates (Fig. $2 C$ ). To minimize adaptation effects, repetition rates were randomly interleaved, and $2 \mathrm{~s}$ of silence separated each train. The 2-s interval between trains allowed the response strength to 0.5 -pps trains to be approximated. The carrier frequency of the tones trains for defining the RRTF were set to be the frequency of the seven used in pairing that was closest to each site's best frequency. To facilitate comparison across recording sites, response amplitude was normalized using the number of spikes evoked at each site to a tone in isolation. The normalized RRTF was defined as the average number of spikes evoked for each of the last five tones in the train divided by the number of spikes evoked by the first tone in the train. Thus a normalized spike rate of one indicates that at the given repetition rate each of the tones in the train, on average, evoked the same number of spikes as the first tone. Values greater than one indicate facilitation, whereas values less than one indicate response adaptation. Only spikes occurring from 5 to $40 \mathrm{~ms}$ after each tone onset were used to calculate the RRTF. RRTF data could not be viewed on-line and were analyzed only after each experiment was completed. All analyses were automated and were therefore not subject to experimenter bias or error. The effect of BF pairing on mean RRTF across all conditions was determined with ANOVA. Pairwise comparisons were analyzed by Fisher's PLSD. Best repetition rate was defined for each site as the repetition rate that evoked the maximum number of spikes.

The accuracy of our stereotaxic implantation of chronic stimulating electrodes into BF was confirmed in eight animals using standard histological techniques. Due to the size of the stimulating electrode and diffuse nature of NB, implantation was highly reliable, as confirmed physiologically each day in every animal.

\section{RE S U L T S}

This report describes the results of experiments conducted to investigate the mechanisms that allow different sensory experiences to generate distinct forms of cortical plasticity. In each experiment, a group of adult rats was exposed to a sound stimulus paired with electrical activation of the BF to gate cortical plasticity. Four weeks of such pairing several hundred times per day generated several distinct forms of cortical plasticity. We report here experience-dependent plasticity generated by 10 variations of tonal stimuli paired with identical $\mathrm{BF}$ activation in 38 adult rats $(\sim 2,000$ A1 penetrations, Table 1$)$. These results are compared with 14 experimentally naïve controls (663 A1 penetrations) and discussed in relation to several studies of experience-dependent plasticity resulting from extensive behavioral training. Because identical $\mathrm{BF}$ activation (strength, number of repetitions, time course, etc.) was used in each experimental group, we conclude that the differential plasticity documented in this study was a result of the differential auditory experience of each group.

To determine the effects of acoustic experience on receptivefield structure, response strength and latency, maximum following rate, and size of A1, we systematically varied four parameters of the acoustic stimuli paired with $\mathrm{BF}$ activation (Table 1). In the first experimental group, 10 rats heard a pure tone paired with $\mathrm{BF}$ activation. In the second group, 10 rats received BF stimulation paired with a tone whose frequency was randomly selected each trial to be one of either two or nine different frequencies (5 rats in each subgroup). This experiment was designed to test the effect of distributing the acoustic experience across the sensory epithelium (cochlea). In the third group, 14 rats received $\mathrm{BF}$ stimulation paired with trains of tones instead of a single tone to determine the parameters that shape temporal response plasticity. To study the effects of both repetition rate and carrier-frequency variability, this group was divided into four subgroups. All the rats in the first subgroup, heard trains of six $9-\mathrm{kHz}$ tones presented at 15 pps paired with $\mathrm{BF}$ activation. In the other three subgroups, the carrier frequency of each tone train was varied from trial to trial (1 of 7 possible carrier frequencies). Rats in these three subgroups heard trains with a repetition rate of $5,7.5$, or $15 \mathrm{pps}$ to demonstrate that the observed plasticity was specific to the paired repetition rate. In the fourth group of rats, a 10-s interval was inserted between the BF stimulation and the onset of a single $19-\mathrm{kHz}$ tone to determine the importance of the relative timing of BF activation and acoustic input. After 4 wk of pairing, we employed well-established cortical mapping techniques to quantify changes in the spectral and temporal response properties of cortical neurons and reconstruct their distributed response.

\section{Receptive field expansion and contraction}

We have previously demonstrated that $\mathrm{BF}$ stimulation can substantially alter the degree of frequency selectivity in A1 neurons (Kilgard and Merzenich 1998a). In this study, we document in detail the relationship between sensory experience and receptive-field size. Specifically, we observed that both the degree and direction of bandwidth plasticity are determined by a combination of the two acoustic parameters varied in this study: number of different tone frequencies and repetition rate (Fig. 3). For example, pairing BF stimulation with a 15-pps train of $9-\mathrm{kHz}$ tones increased the mean bandwidth of A1 neurons by $60 \%$ (Fig. 3, a), while interleaving two different tone frequencies decreased the mean bandwidth by $25 \%$ (Fig. 3 , i). These results mimic the findings in monkeys that several weeks of practice with a modulated stimulus increases receptive-field size, while discriminating between different tone frequencies decreases receptive-field size (Recanzone et al. 1992c, 1993). Although it was argued that the differential plasticity effects observed in those studies contributed to the practice-induced improvements in task performance, the mechanisms that direct these opposite forms of plasticity remain unclear. In our experiments, varying the carrier frequency of the 15-pps tone trains resulted in significantly less receptivefield expansion $(P<0.0001)$ compared with 15 -pps trains with a fixed carrier frequency (Fig. 3, a and b). We also presented tone trains with random carrier frequency and 5- or 7.5-pps repetition rate as part of our experiments on temporal plasticity (Kilgard and Merzenich 1998b). The systematic decrease in receptive field expansion as repetition rate is decreased (Fig. 3, b-d) suggests that cortical plasticity rules shape receptive field size dependent on input repetition rate.

We also observed that unpaired (background) stimuli could 


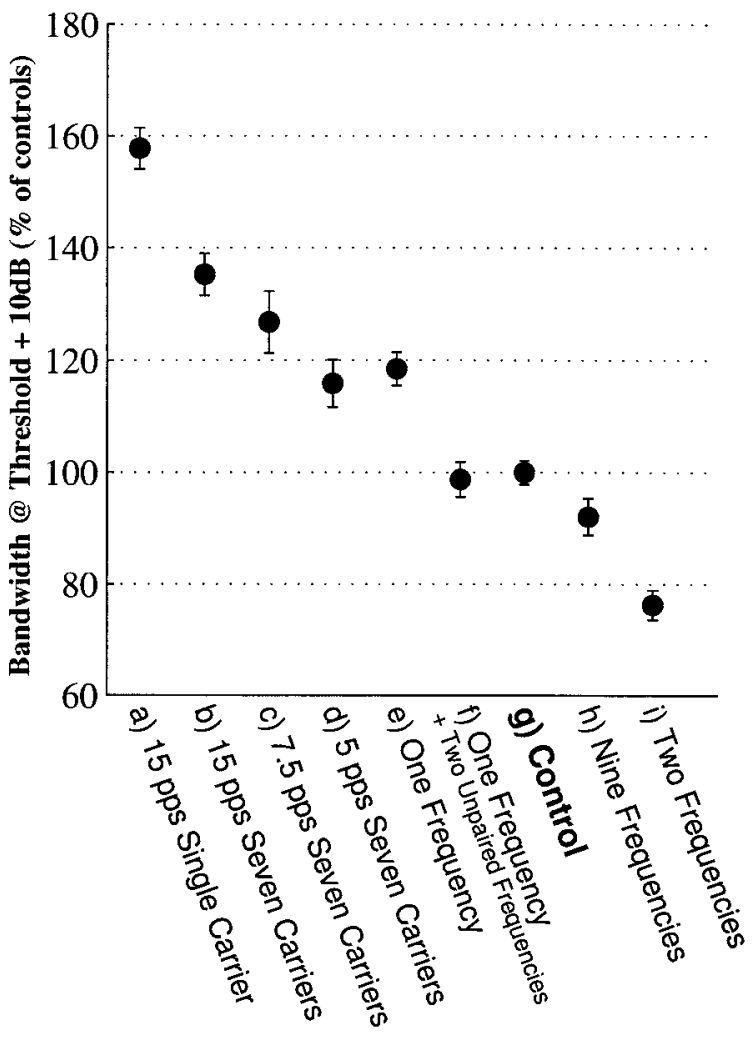

Stimulus Paired with BF Activation

FIG. 3. Bandwidth (receptive field size) of A1 neurons is influenced by specific features of the auditory stimulus paired with $\mathrm{BF}$ activation. Mean bandwidth $10 \mathrm{~dB}$ above threshold with SE (across sites) is shown. Similar trends were observed for BW 20-40. Results did not differ if only sites with best frequencies near the trained frequency(ies) were analyzed. In agreement with training-induced plasticity in monkeys, receptive-field size is increased by stimuli with a high degree of temporal modulation and little spatial (spectral) variability (15-pps trains of $9-\mathrm{kHz}$ tones) and reduced by stimuli with more spatial variability and no temporal modulation $(2$ different frequencies of unmodulated tones). Pairing acoustic stimuli that share features of each resulted in intermediate results. Note: acoustic stimuli were reordered from Table 1 to facilitate comparison of similar effects on BW. All experimental groups had statistically significant $(P<0.05)$ mean BW 10 compared with controls, except f).

influence receptive-field plasticity. Although receptive-field sizes were increased by $20 \%$ when a single tone was paired with $\mathrm{BF}$ activation, frequency selectivity was not affected in a different group of rats that received identical BF pairing with one tone frequency but also heard two additional frequencies that were not paired with BF stimulation (Fig. 3, e-g). This result supports the preceding interpretation that frequency variability tends to minimize receptive field expansion and also reveals an important role of background sounds in shaping cortical plasticity.

\section{Strength of evoked response}

The strength of the evoked response of A1 neurons could also be increased by BF-induced plasticity mechanisms. Of the 10 different sets of acoustic stimulation paired with BF activation, only 1 significantly altered the mean number of spikes evoked per tone. After pairing the 15-pps trains of 9-kHz tones, on average $3.7 \pm 0.2$ spikes per tone were recorded from each A1 penetration compared with $2.8 \pm 0.1$ spikes in experimen- tally naïve rats. This increased excitability was likely caused by the dramatic overlap of receptive fields due to the combination of map reorganization and receptive field broadening. Pairing multiple carrier frequencies with a slow repetition rate (in isolation, 5 or $7 \mathrm{pps}$ ) decreased the spontaneous firing rate (by $\sim 30 \% ; P<0.05$ ) compared with controls.

Previous studies using cholinergic modulation observed highly specific changes in the number of spikes evoked by different tones within a neuron's receptive field. In some cases, the neural response to frequencies within one-fourth of an octave were facilitated, while the responses to other nearby frequencies were inhibited (Bakin and Weinberger 1996; McKenna et al. 1989; Metherate and Weinberger 1989, 1990). Most of the analysis in this study is focused on the receptive field as a unit and would not pick up changes in the response strength to frequencies within the tuning curve. To determine if such precise effects resulted from our long-term pairing of BF activation with tonal stimuli, the number of spikes evoked as a function of frequency was also examined for every tuning curve. We observed no consistent peak at the paired frequency in individual sites or in the population as a whole (data not shown). Minimum stimulus thresholds also showed no consistent change as a result of pairing BF stimulation with any of the auditory stimuli used in this study.

\section{Temporal response plasticity}

Aspects of the sensory input had a significant effect on the latency of A1 responses to tones (Fig. 4). Pairing a slow train of tones with multiple carrier frequencies increased the average minimum response latency by $\sim 1 \mathrm{~ms}$, while pairing a single tone with $\mathrm{BF}$ stimulation ( 1 at a time or in 15-pps trains) decreased onset latencies by $\sim 1 \mathrm{~ms}$. Both of these sets of acoustic stimuli delayed the end of the cortical response (Fig. $4 B)$. The widening of the evoked response after single tone pairing likely reflects the consequences of the expanded cortical map in these animals. In contrast, the increase in latency when the maximum repetition rate is decreased (Kilgard and Merzenich 1998b) supports earlier observations that minimum latency is correlated with maximum following rate (Schreiner et al. 1997). Pairing nine different tones with BF stimulation generated a distinct form of temporal plasticity. The population discharge (response synchrony) was significantly sharpened by an increased onset latency combined with a decreased duration of the cortical response. This result suggests that the statistics of the sensory input determine whether spectral or temporal strategies are used to sharpen the cortical representation of stimuli paired with BF activation. This interpretation is strengthened by our observation that pairing two different tones (intermediate between one and nine tone pairing) caused no change in response latency. Thus our results indicate that the temporal response properties of cortical neurons can be substantially and systematically altered by spatial and temporal features of the sensory environment.

We have previously reported that the maximum repetition rate that A1 neurons can respond to can be increased or decreased depending on the rate of acoustic stimuli paired with BF activation (Kilgard and Merzenich 1998b). Additional experiments indicate that repetition rate is not the only stimulus feature that guides the expression of temporal selectivity. Spectral variability also influenced whether maximum following 
A

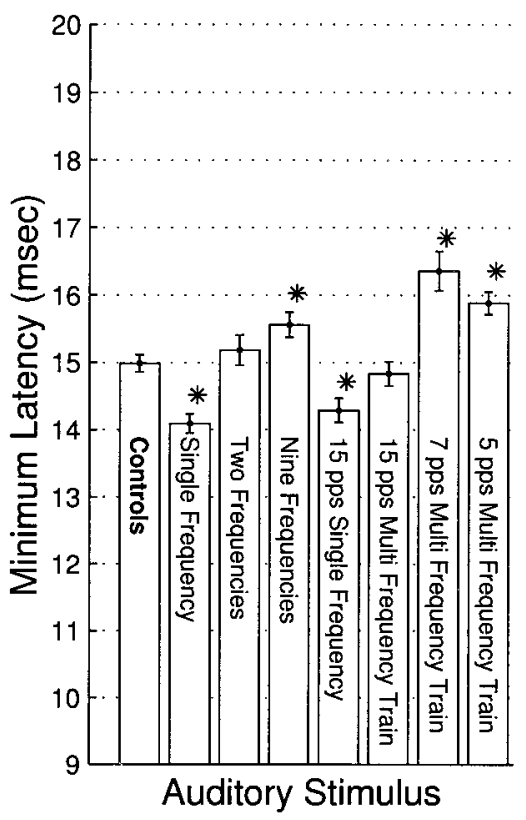

B

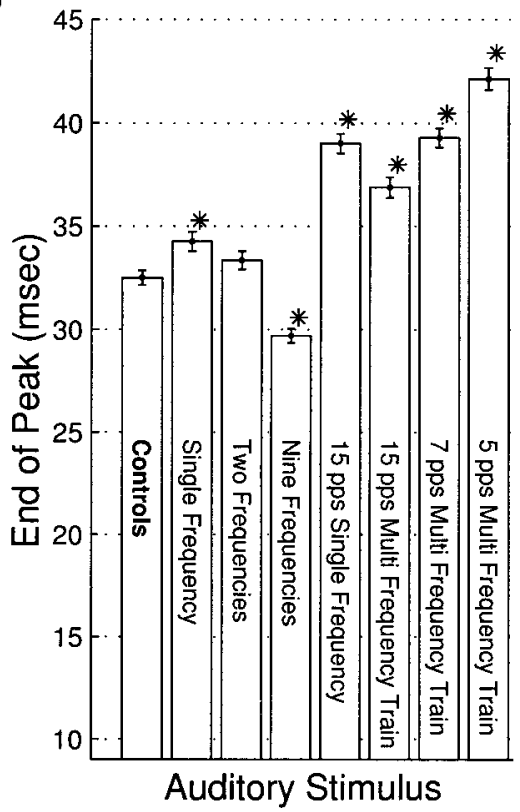

FIG. 4. Latency of A1 neurons. A: minimum latency after pairing tonal stimuli with $\mathrm{BF}$ activation. $B$ : latency to end of peak after pairing. ${ }^{*} P<0.01$ compared with naïve controls. rate was altered. We paired 15 -pps tone trains with BF activation in two groups of animals and quantified the resulting plasticity in following rate by deriving RRTFs at every site. The maximum following rate of cortical neurons was not altered by pairing BF stimulation with $15-\mathrm{pps}, 9-\mathrm{kHz}$ trains (Fig. 5). The profound map reorganization that resulted indicates that the mechanisms of cortical plasticity were successfully engaged (Fig. 6A). In a different set of rats, random carrier frequency 15-pps tone trains were paired with $\mathrm{BF}$ activation to test whether temporal plasticity had been prevented by the extent of map reorganization or whether the 9-kHz carrier frequency had simply been a more salient feature than the repetition rate of 15 pps. Varying the carrier frequency caused the mechanisms of cortical plasticity to significantly increase the cortical following rate (Fig. 5). Although this variation prevented the map reorganization that occurs when a fixed carrier is used (Fig. 6B), it is not clear whether preventing map expansion or increasing the relative saliency of the temporal modulation is a more accurate explanation. Either way this result demonstrates that spectral and temporal characteristics of sounds interact to control spectrotemporal selectivity in cortical neurons. Thus it may be difficult to predict cortical plasticity in response to complex stimuli (i.e., vocalizations) from studies of synaptic mechanisms or cortical plasticity evoked by elemental stimuli.

\section{Expansion of functionally defined AI}

In addition to increasing the percent of A1 that responded to the paired tone frequency (Kilgard and Merzenich 1998a), pairing BF activation with a single frequency increased the total area of A1 by $50 \%$ (Fig. 7). Although this increase in A1 area was based on the well-established functional definition that the primary auditory field has phasic, short-latency responses to tones and a continuous tonotopy (Kilgard and Merzenich 1999; Sally and Kelly 1988), we do not know the effect on anatomical definitions of primary auditory cortex (Roger and Arnault 1989; Romanski and
LeDoux 1993). The observation that the size of A1 was not significantly increased by any of the other stimulus sets paired with BF activation indicates that this form of cortical plasticity is specific to certain forms of acoustic experience (Fig. 7). When the CF shift and overall expansion of A1 are considered together, pairing a single tone with BF stimulation was able to increase the number of A1 neurons responding to the paired tone by threefold.

\section{Frequency map plasticity}

Although map reorganizations occur in some forms of natural learning (Xerri et al. 1994, 1996), such reorganizations typically result from sensory input that is restricted to one region of the topographic map. Learning still occurs in many situations where the distribution of stimuli along the receptor surface precludes map expansion as a possible mechanism. As expected, we observed no significant map plasticity in any of the five rats that heard nine different randomly interleaved unmodulated tones paired with BF activation (data not shown). The increased frequency selectivity and improved temporal synchronization of the cortical response described in the preceding text supports the hypothesis that both receptive field and temporal plasticity contribute to behavioral improvements when it is not possible to increase the number of engaged neurons via map reorganization.

To test the importance of the temporal relationship between $\mathrm{BF}$ activation and sensory input, we delivered BF activation with a $10-\mathrm{s}$ interval before $19-\mathrm{kHz}$ tone presentation. Earlier studies showed that a 1-s separation between sensory input and BF activation caused no short-term BF-induced plasticity (Metherate and Ashe 1991, 1993). In our chronic preparation, a 10 -s separation resulted in a general decrease in frequency tuning (BW10 was $120 \pm 4 \%$ of controls, $P<0.001$ ) but did not result in a specific map expansion at the paired frequency (data not shown). 
A

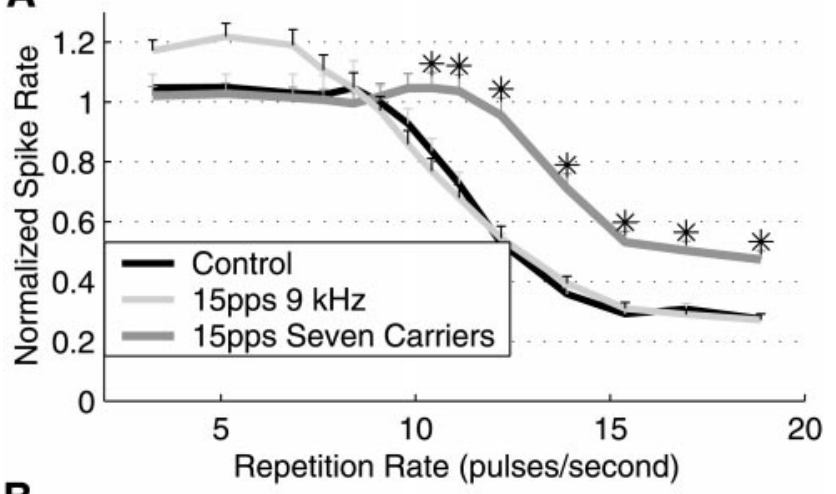

B

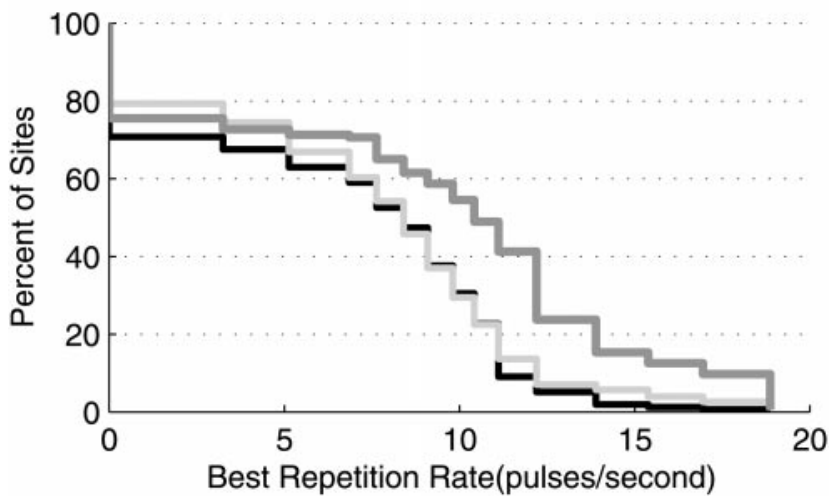

FIG. 5. Temporal plasticity is sensitive to the spectral characteristics of the auditory stimulus. A: pairing 15-pps trains of tones with different carrier frequencies lead to an increase in the strength of the normalized population response to repetition rates above $10 \mathrm{pps}$ compared with controls $\left({ }^{*} P<0.01\right)$, while pairing with 15-pps trains of 9-kHz tones did not significantly affect the mean repetition rate transfer function. $B$ : pairing 15 -pps trains of tones with different carrier frequencies lead to an increase in the percent of sites with a best repetition rates of 12 pps or higher (41 vs. 9\%), while pairing with 15-pps trains of 9-kHz tones did not generate temporal plasticity. The mean best repetition rate in controls was $6.7 \pm 0.4$ pps. After pairing BF activation with 15-pps train, the mean best repetition rate was $7.4 \pm 0.3 \mathrm{pps}$ for $9-\mathrm{kHz}$ trains (not significantly different from naïve controls) and $9.1 \pm 0.5 \mathrm{pps}$ for trains with random carrier frequency $(P<0.001)$.

\section{I S C U S S I O N}

Experimental manipulations of sensory experience can result in a variety of changes in cortical responsiveness (Byrne and
Calford 1991; Hubel and Wiesel 1970). As a class, such effects are generally called experience-dependent plasticity. Merzenich and colleagues observed that different forms of cortical plasticity developed during extended operant training of owl monkeys on several different tasks (Jenkins et al. 1990; Recanzone et al. 1992a,c). Although expansion and sharpening of cortical representations of behaviorally relevant stimuli was a common theme among these studies, the mechanisms that allow the cortex to adapt its processing of sensory information to improve behavioral performance remain unclear. It has been hypothesized that much of the information the cortex uses to determine how to reorganize itself is contained in the sensory input and may even be relatively independent of specific task goals (Ahissar and Ahissar 1994; Merzenich et al. 1990).

This study represents our initial efforts to systematically vary the sensory input to elucidate the "rules" that allow sensory experience to shape both spectral and temporal responses of cortical neurons in adult animals. We used electrical stimulation of $\mathrm{BF}$ to activate cortical plasticity mechanisms and varied only the paired sensory stimuli to explore the relationship between the statistics of the sensory input and the class, direction, and magnitude of cortical reorganization. We report that stimulus repetition rate and spectral variability systematically alter a number of cortical response parameters, including characteristic frequency, frequency bandwidth, size of A1, cortical excitability, stimulus following rate, and response latency (Table 2). The observation that systematic changes in sensory input result in systematic changes in cortical information processing supports the hypothesis that simple rules govern experience-dependent cortical plasticity.

\section{BF-induced spectral and temporal reorganizations}

Our results clarify how specific aspects of the sensory input influences neural selectivity. The receptive-field plasticity recorded in this study provides strong evidence that rules exist in the cortex to translate sensory input into substantive changes in cortical information processing. Frequency bandwidth was particularly sensitive to the auditory stimulus paired with $\mathrm{BF}$ activation. Bandwidth was increased by $60 \%$ or decreased by $25 \%$ simply by pairing different tonal stimuli with identical BF stimulation. Across the range of stimulus classes used in this study, bandwidth increased systematically with increasing rep-
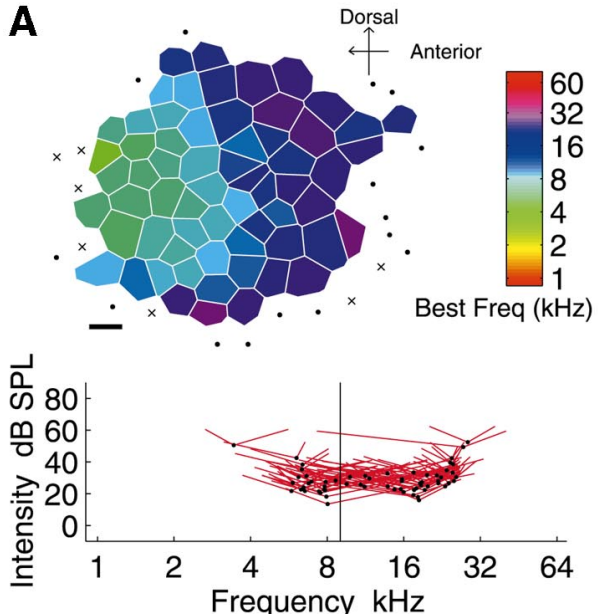
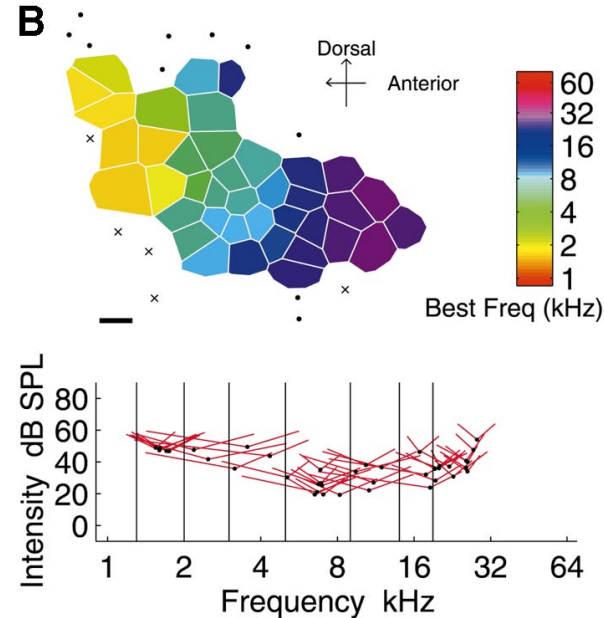

FIG. 6. Maps of best frequency with tuning curves for representative rats that had BF stimulation paired with $9-\mathrm{kHz}$ tone pips presented at 15 pps $(A)$ or 15-pps trains of different carrier frequency tone pips $(B)$ each day for $4 \mathrm{wk}$. When BF stimulation was paired with tone frequencies distributed across A1, no systematic map reorganizations were generated, while using a single carrier frequency generated substantial map plasticity. 


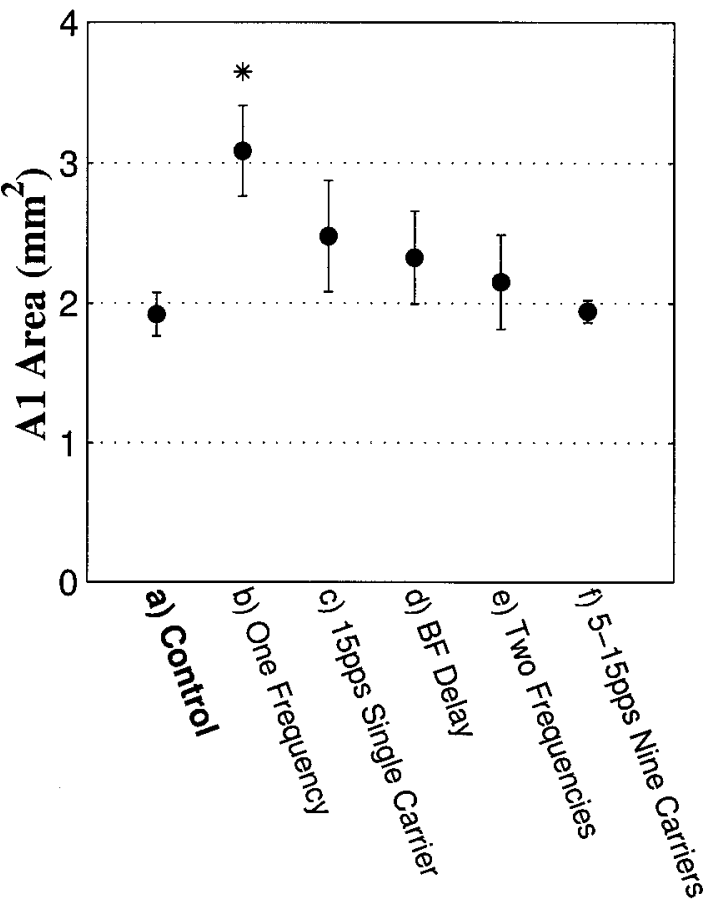

Stimulus Paired with BF Activation

FIG. 7. Total area of A1 was increased when 1 frequency tone was paired with $\mathrm{BF}$ activation but not when other tonal stimuli were paired with $\mathrm{BF}$ activation; $* P<0.01$. A1, was defined based on continuous tonotopy and short response latency (see METHODS).

etition rate and decreased with increasing spectral variability (Fig. 8A).

Merzenich and colleagues observed a similar relationship following operant training of monkeys. Cortical receptive-field size was decreased by practicing tasks with stimuli delivered to different locations on the receptor surface (cochlea or skin) and were increased by training on a task requiring detection of changes in the modulation rate of a stimulus delivered to an invariant skin location (Jenkins et al. 1990; Recanzone et al. 1992a,c). The authors suggest that the observed training-induced changes in receptive-field size were consistent with the operation of Hebb-like synapses driven to change by tempo- rally coherent inputs in a competitive cortical network. Specifically, they postulated that larger receptive fields are generated by the temporally synchronous activity in response to low-frequency $(10-20 \mathrm{~Hz})$ stimulation at an invariant location of the receptor surface, while decreased receptive fields resulted from asynchronous cortical activity in response to stimuli that move across or are applied at inconsistent receptor locations (skin or cochlea). By systematically varying both spectral variability and repetition rate, our study strengthens the argument that receptive-field size is determined by the structure of temporal correlations evoked by input sources and supports the hypothesis that simple rules operate in the cortex to generate useful changes in circuitry based on the statistics of sensory stimuli marked by BF activity.

Our results also support earlier findings that receptive-field plasticity effects are not always limited to the region of the map most strongly activated by the training stimulus. Expansion of somatosensory receptive fields following vibrotactile training using one digit was observed on neighboring digits as well the trained digit (Recanzone et al. 1992c). Statistical analysis of receptive-field size in rats that heard one frequency paired with BF stimulation revealed that expansion also occurred in neurons with CFs up to two octaves away from the paired frequency (data not shown).

$\mathrm{BF}$ stimulation has been shown to increase the number of stimulus-evoked spikes (Bakin and Weinberger 1996; Edeline et al. 1994a,b; Tremblay et al. 1990; Webster et al. 1991b). Of the seven classes of stimuli paired with BF stimulation in this study, only 15-pps trains of $9-\mathrm{kHz}$ tones caused a significant increase in evoked response strength (spikes/tone). Recanzone and colleagues also observed an increase in evoked responses after training monkeys on a task that involved the analogous tactile stimulus (a $20-\mathrm{Hz}$ vibration of a single-digit segment). Thus our findings are consistent with previous demonstrations that response strength plasticity is dependent on particular features of sensory inputs.

Electrical activation of the BF paired with tonal stimuli was sufficient to generate significant reorganization of the A1 frequency map (Kilgard and Merzenich 1998a). The map reorganization combined with a generalized expansion of A1 to generate a threefold increase in the number of cortical neurons

TABLE 2. Schematic summary of experimental results

\begin{tabular}{|c|c|c|c|c|c|c|c|c|}
\hline & CF Shift & A1 Area & RF Size & Spikes/Tone & $\begin{array}{l}\text { Spontaneous } \\
\text { Activity }\end{array}$ & Latency & $\begin{array}{l}\text { End of } \\
\text { Response }\end{array}$ & $\begin{array}{c}\text { Maximum } \\
\text { Following } \\
\text { Rate }\end{array}$ \\
\hline One frequency & $\uparrow \uparrow$ & $\uparrow \uparrow$ & $\uparrow$ & 0 & 0 & $\downarrow \downarrow$ & $\uparrow$ & - \\
\hline Two frequencies & $\uparrow$ & 0 & $\downarrow \downarrow$ & 0 & 0 & 0 & 0 & - \\
\hline Nine frequencies & 0 & 0 & $\downarrow$ & 0 & $\downarrow$ & $\uparrow \uparrow$ & $\downarrow$ & - \\
\hline \multicolumn{9}{|l|}{15 -pps tone trains } \\
\hline $\begin{array}{l}\text { One-carrier } \\
\text { frequency }\end{array}$ & $\uparrow \uparrow$ & 0 & $\uparrow \uparrow \uparrow$ & $\uparrow \uparrow$ & 0 & $\Downarrow$ & $\uparrow$ & 0 \\
\hline Seven-carrier & & & & & & & & \\
\hline frequencies & 0 & 0 & $\uparrow \uparrow$ & 0 & 0 & 0 & $\uparrow$ & $\uparrow \uparrow$ \\
\hline \multicolumn{9}{|l|}{ 5-pps tone trains } \\
\hline $\begin{array}{l}\text { Seven-carrier } \\
\text { frequencies }\end{array}$ & 0 & 0 & $\uparrow$ & 0 & $\downarrow$ & $\uparrow \uparrow$ & $\uparrow \uparrow$ & $\Downarrow$ \\
\hline
\end{tabular}

Both the degree and direction of cortical plasticity [including changes in receptive field structure, primary auditory cortex (A1) area, response strength, temporal selectivity, and response latency] are influenced by the structure and schedule of inputs that co-occur with nucleus basalis activity. The direction and number of arrows indicate direction and magnitude of observed plasticity. Zeros indicate no significant difference from naive controls. Dash indicates not evaluated. 
A

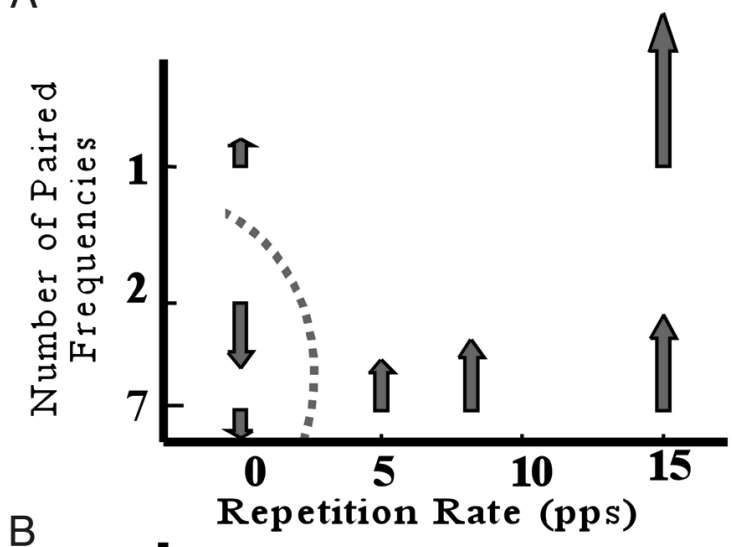

B

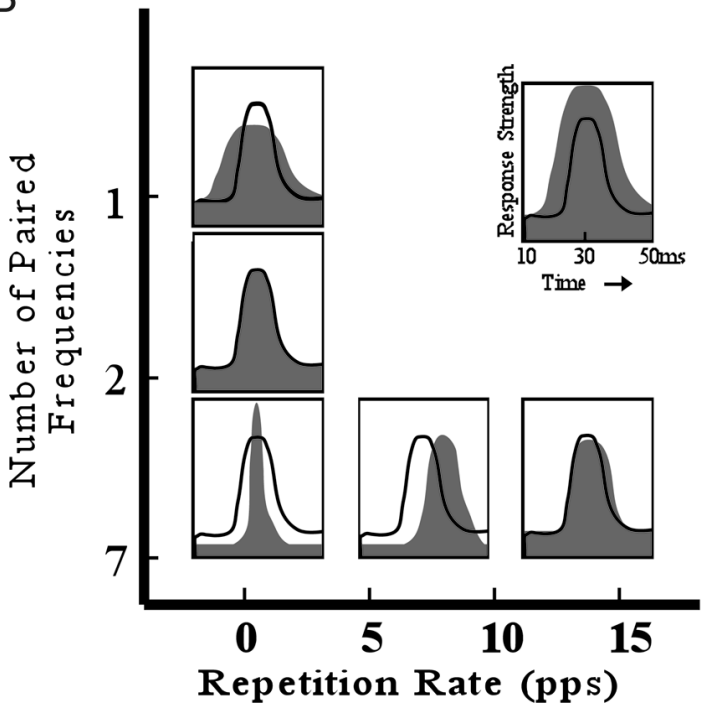

FIG. 8. Spectral and temporal response characteristics are determined by repetition rate and carrier frequency variability. A: schematic relating the degree of receptive-field expansion or contraction to acoustic features of carrier frequency variability and repetition rate. Upward arrows indicate receptive-field expansion, while downward arrows indicate contraction. The length of each arrow is proportional to the observed receptive-field plasticity. The dotted line represents the transition from expansion to contraction. $B$ : schematic relating the plasticity of response strength, latency, and spontaneous rate to the carrier frequency variability and repetition rate of the stimuli paired with $\mathrm{BF}$ activation. Each box provides a schematic view of the tone-evoked response (PSTH) of A1 neurons after pairing $\mathrm{BF}$ activation with different classes of tonal stimuli. The black line indicates the typical response in experimentally naïve rats. Differences in $B$ are exaggerated for illustrative purposes.

that responded to the paired frequency. The direction of tuning curve shift was determined by the frequency of the tones paired with $\mathrm{BF}$ stimulation, while the magnitude of map expansion was determined by the degree of spectral variability of the paired tones. Our results support earlier reports that BF activity generates the most precise cortical plasticity when nearly simultaneous with cortical input (Metherate and Ashe 1991, 1993). This study extends previous reports that the absolute size of a cortical zone could be expanded following some types of behavioral training, if attentional resources were appropriately engaged (Jenkins et al. 1990; Merzenich et al. 1990). We conclude that BF activity is sufficient to mimic these cortical map expansions.

The maximum following rates of A1 neurons were decreased or increased by pairing $\mathrm{BF}$ stimulation with 5- or 15-pps tone trains, respectively (Kilgard and Merzenich 1998b). This report extends those findings by demonstrating that the degree of spectral variability can substantially alter the expression of temporal plasticity in auditory cortex. Pairing a train of $9-\mathrm{kHz}$ tones presented at 15 pps with BF stimulation did not increase the maximum cortical following rate (Fig. 5). This result may explain why the cortical recovery time was not altered by many weeks of training monkeys on a temporally based tactile discrimination task that used spatially restricted input (Recanzone et al. 1992d). In that study, Recanzone and colleagues argued that decreased latency and increased synchronization contributed to improved behavioral performance.

Finally, our finding that response latency is systematically altered by certain classes of acoustic stimuli provides another potential explanation for an earlier plasticity result using monkeys (Fig. 8B). Recanzone and colleagues observed that training monkeys to distinguish a tone standard from a range of other tone frequencies caused minimum latency to increase (Recanzone et al. 1993). As in that study, latency was increased in our study when a range of frequencies was presented (Fig. 8B). However, this increase in minimum latency was accompanied by a decrease in the duration of the cortical response that generated a more synchronous evoked response (and a decrease in spontaneous activity). If the duration of the cortical response in the earlier study (not reported) was decreased, an apparent distinction between the two monkey studies may point to a commonality that more synchronous activation of cortical neurons results from extensive discriminative training. The development of receptive field and temporal refinement when stimuli are distributed across the receptor surface suggests that these mechanisms may support behavioral improvements when map expansion is not possible.

Potential mechanisms that underlie the cortical plasticity documented in this study include changes in network, synaptic, or cell intrinsic properties. Although it is likely that effects at all three levels contributed to the observed changes in spatial and temporal response properties, the simplest explanation of our results is that sensory experience differentially affected the balance of inhibition and excitation. Blocking GABAergic receptors in the auditory cortex results in receptive field expansion, increased response strength, and decreased latency (Chen and Jen 2000; Wang et al. 2000). In our experiments, pairing a 15-pps train of 9-kHz tones with BF activation caused very similar effects (Fig. 8, $A$ and B, top right). Opposite changes in all three response characteristics occurred when unmodulated tones of varying carrier frequency were paired (Fig. 8, $A$ and B, bottom left). Recent computational models with spike-timing-dependent synaptic plasticity have shown that such selective mechanisms can also profoundly affect response latency (Song et al. 2000). Although additional experiments are needed to clarify the mechanisms that underlie these changes, the systematic relationship between sensory experience and cortical plasticity documented in this study suggests that a comprehensive description of the rules that transform experience into useful changes in the distributed cortical response is possible.

Although several studies have reported that the cortical plasticity induced by a single episode of BF stimulation decays rapidly, other studies have observed longer-lasting effects (Bjordahl et al. 1998; Dykes et al. 1990; Edeline et al. 1994a; Hars et al. 1993; Rasmusson and Dykes 1988; Tremblay et al. 1990; Webster et al. 1991b). Shulz and colleagues recently 
demonstrated that in some situations acetylcholine-dependent plasticity is expressed only in the presence of acetylcholine (Shulz et al. 2000). Both the speed of acquisition and volatility of these effects supports their argument that state-dependent levels of neuromodulators control the expression of some forms of cortical plasticity. All of the data presented in this study was collected $24-48 \mathrm{~h}$ after the last electrical activation of BF. Our observation that BF-induced plasticity endures for 1 day and is expressed even under anesthesia suggests that structural changes may contribute to the expression and maintenance of the changes in neural selectivity documented in this study. Thus the duration and size of the plasticity effects generated by repeated BF activation suggest that short-lived BF-induced plasticity can become long-lasting with extended repetition over the course of days to weeks.

\section{Technical considerations}

Although several other studies using BF stimulation have demonstrated that activation of cholinergic receptors is necessary for BF-induced plasticity (Bakin and Weinberger 1996; Edeline et al. 1994b; Hars et al. 1993; Kilgard and Merzenich 1998a; Metherate and Ashe 1991), the role of acetylcholine has not been established in this study. Although we suspect acetylcholine is involved in the plasticity documented in this report, it is also likely that other neurotransmitters released by NB neurons (including GABA) are important regulators as well (Dykes 1997; Gritti et al. 1997). The aim of this study was to clarify how different sounds paired with BF activation lead to different forms of cortical plasticity.

Two types of comparisons were used to quantify the effect of acoustic experience paired with BF activation. In the first, cortical responses from experimentally naïve rats were compared with responses from rats that had received 4 wk of BF stimulation. This across-animal design was necessary due to the difficulty with generating a detailed reconstruction of the cortical map before and after pairing in individual animals. Rats were randomly selected to serve as control or experimental animals. Thus the responses of A1 neurons in naïve animals should be equivalent to responses in experimental animals prior to BF stimulation, and significant differences with this group reflect experimentally induced plasticity. The second class of comparisons were between groups of rats that had received identical BF stimulation and differed only in their acoustic experience. These comparisons establish the specificity of the plasticity effects documented in this study and rule out the possibility that the observed changes in cortical responses arose due to $\mathrm{BF}$ implantation or other nonspecific effects.

Although BF activation occurred only in unanesthetized animals, the neural responses analyzed in this study were collected under barbiturate anesthesia. Cortical responses are unlikely to be identical in awake and anesthetized animals; however, basic response features of barbiturate anesthetized cortex, such as frequency tuning and repetition rate transfer functions, are at least qualitatively similar to the awake state (deCharms et al. 1998; Hars et al. 1993; Recanzone et al. 2000; Shamma and Symmes 1985). In this study, all of the comparisons of neural responses were between rats anesthetized in a similar manner. Thus anesthesia is unlikely to be responsible for the differential plasticity documented here.

\section{Basal forebrain and learning}

Nucleus basalis neurons located in the basal forebrain respond vigorously to behaviorally important stimuli, either aversive or rewarding (Richardson and DeLong 1991). Our data are consistent with the hypothesis that an important function of this activity is to mark individual events as behaviorally relevant so that cortical plasticity mechanisms can improve the representations of important stimuli (Ahissar and Ahissar 1994; Richardson and DeLong 1991; Singer 1986; Weinberger 1993). Although essential for effective learning, identifying behaviorally important stimuli represents only an initial step toward generating an improved cortical representation that might be behaviorally useful. Individual neurons must not only alter their response properties based only on their synaptic inputs; they must do so in a concerted manner that leads to an improved distributed response.

Although it seems obvious that the representation of a tone would be improved by increasing the number of neurons tuned for the tone's frequency, in fact, the ideal solution depends entirely on what information is needed from the stimulus. If an animal is conditioned that a tonal stimulus predicts footshock, there is no way to know which features of the stimulus will predict shock in the future (frequency, duration, rise time, bandwidth, intensity, modulation rate, etc.). The fact that animals generalize indicates that they do not assume that all of the features are required. Evolution may have shaped brain circuitry to make default guesses that are appropriate based on the evolutionary history of the species (i.e., phyletic memory) (see Fuster 1995). These guesses may take the form of rules that operate within the brain to extract stimulus features that are most likely to contain relevant information.

A substantial amount of literature now demonstrates that different behavioral tasks result in different forms of representational plasticity in the cortex. Although the relationship between stimulus representation and information processing is far from clear, the similarity between the results in this study and earlier reports of cortical plasticity evoked by extended behavioral training suggests that the sensory input itself can provide much of the information about how to improve sensory representations. In this initial study we have focused on two stimulus features, repetition rate and spectral variability, and observed that each effected cortical plasticity in a systematic manner (Fig. 8). These results indicate that the cortex uses these features to guide several forms of cortical plasticity, including reorganization of feature maps, plasticity of spectral and temporal selectivity, expansion of a primary sensory cortical field, and increased strength of evoked responses. Additional experiments are needed to determine how other stimulus parameters shape representational plasticity.

We thank D. Rathbun, A. Cheney, N. Engineer, and R. Moucha for technical assistance; D. Buonomano, H. Mahncke, D. Blake, S. Nagarajan, P. Bedenbaugh, E. Ahissar, and H. Read for helpful discussion; and J.-M. Edeline, A. Doupe, A. Bausbaum, W. Martin, K. Miller, E. Knudsen, and two anonymous reviewers for insightful comments on the manuscript.

This work was supported by National Institute of Neurological Disorders and Stroke Grant NS-10414, Office of Naval Research Grant N00014-96-102, Hearing Research, Inc., and a National Science Foundation Predoctoral Fellowship (M. P. Kilgard).

\section{REFERENCES}

AHISSAR E AND AHISSAR M. Plasticity in auditory cortical circuitry. Curr Opin Neurobiol 4: 580-587, 1994. 
Ahissar E, Vaadia E, Ahissar M, Bergman H, Arieli A, and Abeles M. Dependence of cortical plasticity on correlated activity of single neurons and on behavioral context. Science 257: 1412-1415, 1992.

AHISSAR M AND HoCHSTEIN S. Task difficulty and the specificity of perceptual learning. Nature 387: 401-406, 1997.

BAKIN JS, LePAN B, AND WeInBERGER NM. Sensitization induced receptive field plasticity in the auditory cortex is independent of CS-modality. Brain Res 577: 226-235, 1992.

BAKIN JS, SOUTH DA, AND WEINBERGER NM. Induction of receptive field plasticity in the auditory cortex of the guinea pig during instrumental avoidance conditioning. Behav Neurosci 110: 905-913, 1996.

BAKIN JS AND WEINBERGER NM. Induction of a physiological memory in the cerebral cortex by stimulation of the nucleus basalis. Proc Natl Acad Sci USA 93: 11219-11224, 1996

BASKerville KA, Schweitzer JB, AND Herron P. Effects of cholinergic depletion on experience-dependent plasticity in the cortex of the rat. Neuroscience 80: 1159-1169, 1997

BEAR MF AND Singer W. Modulation of visual cortical plasticity by acetylcholine and noradrenaline. Nature 320: 172-176, 1986.

BJoRDAhl TS, Dimyan MA, AND WeINBERGER NM. Induction of long-term receptive field plasticity in the auditory cortex of the waking guinea pig by stimulation of the nucleus basalis. Behav Neurosci 112: 467-479, 1998.

Buonomano DV and Merzenich MM. Cortical plasticity: from synapses to maps. Апnи Rev Neurosci 21: 149-186, 1998.

Byl NN, Merzenich MM, AND Jenkins WM. A primate genesis model of focal dystonia and repetitive strain injury. I. Learning-induced dedifferentiation of the representation of the hand in the primary somatosensory cortex in adult monkeys. Neurology 47: 508-520, 1996.

BYRNE JA AND CALFORD MB. Short-term expansion of receptive fields in rat primary somatosensory cortex after hindpaw digit denervation. Brain Res 565: 218-224, 1991

ChEN QC AND JEN PH. Bicuculline application affects discharge patterns, rate-intensity functions, and frequency tuning characteristics of bat auditory cortical neurons. Hear Res 150: 161-174, 2000.

DeCharms RC, Blake DT, and MerZenich MM. Optimizing sound features for cortical neurons. Science 280: 1439-1443, 1998.

DiAMOND DM AND WeINBERGER NM. Role of context in the expression of learning-induced plasticity of single neurons in auditory cortex. Behav Neurosci 103: 471-494, 1989.

DimYAN MA AND WEINBERGER NM. Basal forebrain stimulation induces discriminative receptive field plasticity in the auditory cortex. Behav Neurosci 113: 691-702, 1999.

DYKES RW. Mechanisms controlling neuronal plasticity in somatosensory cortex. Can J Physiol Pharmacol 75: 535-545, 1997.

Dykes R, METHERATE R, AND TREmblay N. Transient and prolonged effects of acetylcholine on responsiveness of cat somatosensory cortical neurons (Letter). J Neurophysiol 63: 223, 1990.

EDELINE JM. Learning-induced physiological plasticity in the thalamo-cortical sensory systems: a critical evaluation of receptive field plasticity, map changes and their potential mechanisms. Prog Neurobiol 57: 165-224, 1999.

Edeline JM, Hars B, Maho C, and Hennevin E. Transient and prolonged facilitation of tone-evoked responses induced by basal forebrain stimulations in the rat auditory cortex. Exp Brain Res 97: 373-386, 1994a.

EDELINE JM, MAHO C, HARS B, AND HENNEVIN E. Non-awaking basal forebrain stimulation enhances auditory cortex responsiveness during slow-wave sleep. Brain Res 636: 333-337, 1994b.

Edeline JM, Pham P, AND Weinberger NM. Rapid development of learninginduced receptive field plasticity in the auditory cortex. Behav Neurosci 107: 539-551, 1993.

EDELINE JM AND WEINBERGER NM. Receptive field plasticity in the auditory cortex during frequency discrimination training: selective retuning independent of task difficulty. Behav Neurosci 107: 82-103, 1993.

Fuster JM. Memory in the Cerebral Cortex. Cambridge, MA: MIT Press, 1995

GILBERT CD. Adult cortical dynamics. Physiol Rev 78: 467-485, 1998.

GLAZEWSKI S. Experience-dependent changes in vibrissae evoked responses in the rodent barrel cortex. Acta Neurobiol Exp 58: 309-320, 1998.

Gritti I, Mainville L, Mancia M, and Jones BE. GABAergic and other noncholinergic basal forebrain neurons, together with cholinergic neurons, project to the mesocortex and isocortex in the rat. J Comp Neurol 383: $163-177,1997$

HARING JH AND WANG RY. The identification of some sources of afferent input to the rat nucleus basalis magnocellularis by retrograde transport of horseradish peroxidase. Brain Res 366: 152-158, 1986.
Hars B, Maho C, Edeline JM, and Hennevin E. Basal forebrain stimulation facilitates tone-evoked responses in the auditory cortex of awake rat. $\mathrm{Neu}$ roscience 56: 61-74, 1993

HASSELMO ME. Neuromodulation and cortical function: modeling the physiological basis of behavior. Behav Brain Res 67: 1-27, 1995.

HowARD MA 3RD AND SIMONS DJ. Physiologic effects of nucleus basalis magnocellularis stimulation on rat barrel cortex neurons. Exp Brain Res 102: 21-33, 1994

Hubel DH AND WIESEL TN. The period of susceptibility to the physiological effects of unilateral eye closure in kittens. J Physiol (Lond) 206: 419-436, 1970.

Jenkins WM, Merzenich MM, Ochs MT, Allard T, and Guic-Robles E. Functional reorganization of primary somatosensory cortex in adult owl monkeys after behaviorally controlled tactile stimulation. J Neurophysiol 63: 82-104, 1990.

Jimenez-CAPDEville ME, Dykes RW, and Myasnikov AA. Differential control of cortical activity by the basal forebrain in rats: a role for both cholinergic and inhibitory influences. J Comp Neurol 381: 53-67, 1997.

JuLIano SL. Mapping the sensory mosaic. Science 279: 1653-1654, 1998.

JULIANO SL, MA W, AND ESLIN D. Cholinergic depletion prevents expansion of topographic maps in somatosensory cortex. Proc Natl Acad Sci USA 88: 780-784, 1991

Katz LC and Shatz CJ. Synaptic activity and the construction of cortical circuits. Science 274: 1133-1138, 1996

Kelly JB and Masterton B. Auditory sensitivity of the albino rat. $J$ Comp Physiol Psychol 91: 930-936, 1977.

KILGARD MP AND MERZENICH MM. Cortical map reorganization enabled by nucleus basalis activity. Science 279: 1714-1718, 1998a.

KILGARD MP AND MERZENICH MM. Plasticity of temporal information processing in the primary auditory cortex. Nat Neurosci 1: 727-731, 1998b.

KiLGaRD MP and MERZENICH MM. Distributed representation of spectral and temporal information in rat primary auditory cortex. Hear Res 134: 16-28, 1999.

LeVey AI, Hallanger AE, and Wainer BH. Cholinergic nucleus basalis neurons may influence the cortex via the thalamus. Neurosci Lett 74: 7-13, 1987.

McKenna TM, Ashe JH, And Weinberger NM. Cholinergic modulation of frequency receptive fields in auditory cortex. I. Frequency-specific effects of muscarinic agonists. Synapse 4: 30-43, 1989.

Merzenich MM, Recanzone GH, Jenkins WM, and GrajSki KA. Adaptive mechanisms in cortical networks underlying cortical contributions to learning and nondeclarative memory. Cold Spring Harb Symp Quant Biol 55: 873-887, 1990

Merzenich M, Wright B, Jenkins W, Xerri C, Byl N, Miller S, and TALLAL P. Cortical plasticity underlying perceptual, motor, and cognitive skill development: implications for neurorehabilitation. Cold Spring Harb Symp Ouant Biol 61: 1-8, 1996.

Mesulam MM, Mufson EJ, Wainer BH, and Levey AI. Central cholinergic pathways in the rat: an overview based on an alternative nomenclature (Ch1-Ch6). Neuroscience 10: 1185-1201, 1983.

Metherate R AND Ashe JH. Basal forebrain stimulation modifies auditory cortex responsiveness by an action at muscarinic receptors. Brain Res 559: $163-167,1991$.

Metherate R AND Ashe JH. Nucleus basalis stimulation facilitates thalamocortical synaptic transmission in the rat auditory cortex. Synapse 14: 132$143,1993$.

Metherate R AND WeInBerger NM. Acetylcholine produces stimulus-specific receptive field alterations in cat auditory cortex. Brain Res 480: 372-377, 1989 .

Metherate R AND Weinberger NM. Cholinergic modulation of responses to single tones produces tone-specific receptive field alterations in cat auditory cortex. Synapse 6: 133-145, 1990.

PIRCH JH. Basal forebrain and frontal cortex neuron responses during visual discrimination in the rat. Brain Res Bull 31: 73-83, 1993.

Rasmusson DD, Clow K, aND Szerb JC. Frequency-dependent increase in cortical acetylcholine release evoked by stimulation of the nucleus basalis magnocellularis in the rat. Brain Res 594: 150-154, 1992.

RASMUSSON DD AND DYKES RW. Long-term enhancement of evoked potentials in cat somatosensory cortex produced by co-activation of the basal forebrain and cutaneous receptors. Exp Brain Res 70: 276-286, 1988.

ReCANZONE GH, Guard DC, AND Phan ML. Frequency and intensity response properties of single neurons in the auditory cortex of the behaving macaque monkey. J Neurophysiol 83: 2315-2331, 2000. 
Recanzone GH, Merzenich MM, and Dinse HR. Expansion of the cortical representation of a specific skin field in primary somatosensory cortex by intracortical microstimulation. Cereb Cortex 2: 181-196, 1992a.

Recanzone GH, Merzenich MM, and Jenkins WM. Frequency discrimination training engaging a restricted skin surface results in an emergence of a cutaneous response zone in cortical area 3a. J Neurophysiol 67: 1057-1070, $1992 b$.

Recanzone GH, Merzenich MM, Jenkins WM, Grajski KA, and Dinse HR. Topographic reorganization of the hand representation in cortical area $3 \mathrm{~b}$ owl monkeys trained in a frequency-discrimination task. J Neurophysiol 67: 1031-1056, 1992c.

Recanzone GH, Merzenich MM, and Schreiner CE. Changes in the distributed temporal response properties of SI cortical neurons reflect improvements in performance on a temporally based tactile discrimination task. J Neurophysiol 67: 1071-1091, 1992d.

Recanzone GH, Schreiner CE, and Merzenich MM. Plasticity in the frequency representation of primary auditory cortex following discrimination training in adult owl monkeys. J Neurosci 13: 87-103, 1993.

Richardson RT and DeLong MR. Electrophysiological studies of the functions of the nucleus basalis in primates. Adv Exp Med Biol 295: 233-252, 1991.

Roger M AND ARnault P. Anatomical study of the connections of the primary auditory area in the rat. J Comp Neurol 287: 339-356, 1989.

RoMANSKI LM AND LEDoux JE. Organization of rodent auditory cortex: anterograde transport of PHA-L from MGv to temporal neocortex. Cereb Cortex 3: 499-514, 1993.

SACHDEv RN, Lu SM, WiLEY RG, AND EbNER FF. Role of the basal forebrain cholinergic projection in somatosensory cortical plasticity. J Neurophysiol 79: 3216-3228, 1998.

SAKai M, Kudoh M, and ShibuKi K. Long-lasting enhancement of sound discrimination ability after sound exposure in rats. Neurosci Res 33: 87-97, 1999.

SALly SL AND Kelly JB. Organization of auditory cortex in the albino rat: sound frequency. J Neurophysiol 59: 1627-1638, 1988.

Schreiner CE, Mendelson J, Raggio MW, Brosch M, and Krueger K. Temporal processing in cat primary auditory cortex. Acta Otolaryngol Suppl (Stockh) 532: 54-60, 1997.

Shamma SA AND Symmes D. Patterns of inhibition in auditory cortical cells in awake squirrel monkeys. Hear Res 19: 1-13, 1985.

Shulz DE, Sosnik R, Ego V, Haidarliu S, and Ahissar E. A neuronal analogue of state-dependent learning. Nature 403: 549-553, 2000.

SINGER W. The brain as a self-organizing system. Eur Arch Psychiatry Neurol Sci 236: 4-9, 1986.
SINGER W. Development and plasticity of cortical processing architectures. Science 270: 758-764, 1995.

Song S, MilLER KD, AND ABbott LF. Competitive Hebbian learning through spike-timing-dependent synaptic plasticity. Nat Neurosci 3: 919-926, 2000.

Spengler F, Roberts TP, Poeppel D, Byl N, Wang X, Rowley HA, AND MERZENICH MM. Learning transfer and neuronal plasticity in humans trained in tactile discrimination. Neurosci Lett 232: 151-154, 1997.

TREMblay N, WarRen RA, AND DYKES RW. Electrophysiological studies of acetylcholine and the role of the basal forebrain in the somatosensory cortex of the cat. II. Cortical neurons excited by somatic stimuli. J Neurophysiol 64: 1212-1222, 1990.

Wang J, Caspary D, and Salvi RJ. GABA-A antagonist causes dramatic expansion of tuning in primary auditory cortex. Neuroreport 11 : 1137-1140, 2000.

Wang X, Merzenich MM, Sameshima K, and Jenkins WM. Remodelling of hand representation in adult cortex determined by timing of tactile stimulation. Nature 378: 71-75, 1995.

Webster HH, Hanisch UK, Dykes RW, and Biesold D. Basal forebrain lesions with or without reserpine injection inhibit cortical reorganization in rat hindpaw primary somatosensory cortex following sciatic nerve section. Somatosens Mot Res 8: 327-346, 1991a.

Webster HH, Rasmusson DD, Dykes RW, Schliebs R, Schober W, BruckNER G, AND BIESOLD D. Long-term enhancement of evoked potentials in raccoon somatosensory cortex following co-activation of the nucleus basalis of Meynert complex and cutaneous receptors. Brain Res 545: 292-296, 1991b.

WEINBERGER NM. Learning-induced changes of auditory receptive fields. Curr Opin Neurobiol 3: 570-577, 1993.

Whalen PJ, KaPp BS, AND PASCOE JP. Neuronal activity within the nucleus basalis and conditioned neocortical electroencephalographic activation. J Neurosci 14: 1623-1633, 1994.

Woody CD. Acquisition of conditioned facial reflexes in the cat: cortical control of different facial movements. Fed Proc 41: 2160-2168, 1982.

Xerri C, Coq JO, Merzenich MM, and Jenkins WM. Experience-induced plasticity of cutaneous maps in the primary somatosensory cortex of adult monkeys and rats. J Physiol Paris 90: 277-287, 1996

Xerri C, Stern JM, AND Merzenich MM. Alterations of the cortical representation of the rat ventrum induced by nursing behavior. J Neurosci 14 : 1710-1721, 1994.

Zhu XO AND Waite PM. Cholinergic depletion reduces plasticity of barrel field cortex. Cereb Cortex 8: 63-72, 1998.

Zohary E, Celebrini S, Britten KH, and Newsome WT. Neuronal plasticity that underlies improvement in perceptual performance. Science 263: 12891292, 1994 